\title{
To graft or not to graft? Do coronary artery characteristics influence early outcomes of coronary artery bypass surgery? Analysis of coronary anastomoses of 5171 patients
}

\author{
Dumbor L. Ngaage, MSc, FWACS, FETCS, FRCS (C-Th), Imranullah Hashmi, MBBS, \\ Steven Griffin, FRCS(C-Th), Michael E. Cowen, FRCS, Alexander R. Cale, MD, FRCS (C-Th), and \\ Levent Guvendik, FRCS
}

\begin{abstract}
Objective: Small coronary size and extensive atherosclerosis pose operative challenges during coronary artery bypass grafting. We investigated the influence of coronary characteristics on early operative outcome.

Methods: Prospectively collected data for 5171 patients undergoing first-time coronary artery bypass grafting from April 1, 1999, to December 31, 2007, were analyzed. Coronary diameter estimated or probe-gauged intraoperatively was regarded as small if $1.25 \mathrm{~mm}$ or less. Coronary atherosclerosis was graded as none/mild or moderate/severe. Their influence on postoperative major adverse cardiac events, myocardial infarction or reintervention for graft failure, post-cardiotomy shock, and operative mortality, was investigated.
\end{abstract}

\begin{abstract}
Results: Of 14,019 coronary anastomoses, 4417 coronaries (31.5\%) were small and 5895 coronaries $(43.4 \%)$ had moderate/severe atherosclerosis. All grafted coronaries were small in 1091 patients $(21.1 \%)$. Left anterior descending, circumflex, and right coronary arteries received grafts in $94.8 \%$ of patients $(\mathrm{n}=4903), 74.3 \%$ of patients $(\mathrm{n}=3842)$, and $72.5 \%$ of patients $(\mathrm{n}=3751)$, with corresponding rates of $31.7 \%, 31.7 \%$, and $32.6 \%$ for small-caliber arteries, $44.4 \%, 33.3 \%$, and $47.2 \%$ for moderate/severe atherosclerosis, and $0.6 \%, 0.5 \%$, and $3.4 \%$ for endarterectomy. Postoperative major adverse cardiac events occurred in 236 patients $(4.6 \%)$. There was no clear evidence that small caliber of half or more distal anastomoses in a patient (odds ratio, 1.36 ; $95 \%$ confidence interval, $0.97-1.94 ; P=.07$ ) increased the risk of a major adverse cardiac event, but incomplete revascularization (odds ratio, 1.87; 95\% confidence interval, $1.03-3.39 ; P=.04$ ) and moderate/severe atherosclerosis of the left anterior descending artery (odds ratio $1.37 ; 95 \%$ confidence interval, $1.01-1.87 ; P=.04$ ) did increase the risk.
\end{abstract}

Conclusion: Grafting small coronaries did not significantly increase the risk of an early postoperative major adverse cardiac event, but incomplete revascularization did increase the risk. Our findings support grafting small coronaries when technically feasible to prevent incomplete revascularization. (J Thorac Cardiovasc Surg 2010;140:66-72)

\section{Supplemental material is available online.}

Earn CME credits at

http://cme.ctsnetjournals.org

The aggressive pursuit of nonsurgical revascularization selects patients with challenging coronary artery disease for surgical revascularization. ${ }^{1,2}$ Because surgery is preferred to angioplasty and stenting for diabetic patients, ${ }^{3,4}$

From the Cardiothoracic Centre, Castle Hill Hospital, Kingston-Upon-Hull, East Yorkshire, United Kingdom.

Disclosures: None.

Received for publication July 29, 2008; revisions received Aug 12, 2009; accepted for publication Sept 11, 2009; available ahead of print Nov 12, 2009.

Address for reprints: Dumbor L. Ngaage, MSc, FWACS, FETCS, FRCS (C-Th), Department of Cardiothoracic Surgery, Castle Hill Hospital, Kingston-Upon-Hull, East Yorkshire HU16 5JQ, United Kingdom (E-mail: dngaage@yahoo.com).

$0022-5223 / \$ 36.00$

Copyright (c) 2010 by The American Association for Thoracic Surgery doi:10.1016/j.jtcvs.2009.09.029 the increasing number of this cohort of patients undergoing coronary artery bypass grafting (CABG) also contributes to this problem. Not infrequently therefore, intraoperative decisions regarding the suitability for, and prognostic benefit of, grafting these difficult coronaries become a dilemma.

The impact of grafting small coronary arteries on the outcome of CABG is not clear. Attempts to explain the comparatively poor operative outcomes in female patients by smaller-caliber coronary circulation have been unsuccessful. ${ }^{5}$ A similar notion as the cause for the difference in operative outcome between Caucasian and UK South Asian men has not been substantiated. ${ }^{6}$ To address this problem, early studies ${ }^{7-9}$ used a cutoff of $1.5 \mathrm{~mm}$ in diameter to define small coronaries, but in current practice this coronary size would not be considered small. An additional setback of these historical series is their assessment of the impact of the size of a single coronary artery, the left anterior descending artery in most cases, ${ }^{10,11}$ in the era when the left internal thoracic artery was not routinely used for bypass grafting. Furthermore, the influence of other coronary characteristics frequently coexistent with small luminal diameter (eg, severe atherosclerosis) was not investigated. 


\section{Abbreviations and Acronyms \\ $\mathrm{CABG}=$ coronary artery bypass grafting \\ $\mathrm{CI}=$ confidence interval \\ ECG = electrocardiogram \\ MACE $=$ major adverse cardiac event \\ $\mathrm{OR} \quad=$ odds ratio}

In the current era, with improved surgical techniques, regular use of the left internal thoracic artery, and better perioperative care, the implications of constructing anastomoses on small target coronary arteries or severely atherosclerotic vessels are not clearly defined. If these vessels are left ungrafted, however, the resulting incomplete myocardial revascularization imposes prognostic liabilities for both early and late outcomes. ${ }^{12}$

This retrospective study investigated the coronary artery diameter and severity of atherosclerosis in the 3 major territories of the coronary circulation in patients who underwent primary isolated CABG. The study objectives were to (1) assess the prevalence and distribution of coronary arteries with small luminal diameter $(\leq 1.25 \mathrm{~mm})$ and moderate/severe coronary atherosclerosis; (2) examine the relationship between these coronary characteristics and early major adverse cardiac events (MACEs); the combined end points of postoperative myocardial infarction/reintervention for early graft failure, postcardiotomy shock, and operative mortality; and (3) determine the incidence of incomplete myocardial revascularization and its impact on early postoperative MACE.

\section{MATERIALS AND METHODS Patients}

Clinical data are prospectively collected for all patients undergoing cardiac surgery at the university teaching hospital of Castle Hill Hospital and stored in an electronic database. The database is run by dedicated data managers who regularly update and validate entries. After approval was obtained from the local medical and ethics committee and a waiver for individual patient consent, the database was interrogated, and demographic, preoperative, intraoperative, and postoperative data were retrieved for each patient who underwent isolated primary CABG at Castle Hill Hospital between April 1, 1999, and December 31, 2007.

During this period, CABG was performed predominantly with cardiopulmonary bypass and blood cardioplegic or crossclamp fibrillatory arrest; off-pump CABG constituted $7.3 \%$ of procedures $(n=379)$. Our main revascularization strategy involved grafting the left internal thoracic artery to the left anterior descending artery and saphenous vein conduits, harvested by the open technique, to other coronary artery targets. Other arterial conduits, such as the radial $(\mathrm{n}=585)$ and right internal thoracic arteries $(n=148)$, were used less frequently. All anastomoses were hand-sewn, and intraoperative patency was crudely assessed by resistance to the infusion of blood or blood cardioplegia through the graft after constructing the distal anastomoses. After surgery, $300 \mathrm{mg}$ of aspirin was administered per rectum within 6 hours and continued orally at $75 \mathrm{mg}$ daily from the first postoperative day. Blood pressure, heart rate, central venous pressure electrocardiographic tracings, oxygen saturation, and urinary output were continuously monitored for 48 hours postoperatively. Routine 12-lead electrocardiograms (ECGs) were performed on the first, second, and fourth or fifth postoperative days. Whenever a cardiac event was suspected, a 12-lead ECG, an assay of cardiac biomarker levels (although less consistently) (creatine kinase-MB in the early study period and troponin $\mathrm{T}$ in the later period), and transesophageal echocardiography were performed. Reintervention for ischemic ECG changes with hemodynamic deterioration involved reopening and regrafting for occluded grafts, unkinking grafts, and releasing extrinsic graft compression. Angioplasty was performed in 2 stable patients who had recurrent myocardial ischemia with persistent ECG changes after 5 postoperative days.

\section{Definitions}

Coronary artery characteristics were defined on the basis of intraoperative findings. Target coronary arteries were visually assessed, palpated, and calibrated with a probe after arteriotomy. The coronary diameter was recorded as $1.0 \mathrm{~mm}, 1.25 \mathrm{~mm}, 1.5 \mathrm{~mm}, 1.75 \mathrm{~mm}, 2.0 \mathrm{~mm}$, or greater than $2.0 \mathrm{~mm}$. Severity of coronary atherosclerosis was graded as none, mild (discrete isolated plaques on anterior or posterior wall, not at site of arteriotomy or beyond), moderate (plaques on both anterior and posterior walls, with arteriotomy sometimes encroaching on plaques), or severe (diffuse atherosclerosis extends beyond arteriotomy site).

Coronary arteries were classified as small if their diameter was $1.25 \mathrm{~mm}$ or less, and the extent of coronary atherosclerosis was dichotomized into none/mild and moderate/severe. Of 5500 patients in the database, 324 were excluded from the study because they did not have complete entries for the coronary artery diameter, extent of atherosclerosis (principal independent variables, $\mathrm{n}=228$ ), or postoperative MACE (dependent variable, $\mathrm{n}=96$ ). Myocardial revascularization was considered incomplete if any of 3 ischemic territories with coronary stenoses greater than $70 \%$ did not receive a bypass graft.

\section{Statistical Analysis}

The study primary end point was MACE, a composite of 1) postoperative myocardial infarction (new and persistent S-T changes or new $\mathrm{Q}$ waves on electrocardiography) or reintervention for early graft failure in the form of regrafting a coronary artery or angioplasty/stenting; 2) postcardiotomy shock requiring mechanical support with intraaortic balloon pump or ventricular assist device in addition to inotropes; and 3) operative mortality (death during hospitalization or within 30 days of surgery).

Categoric variables are reported as percentages, continuous variables with symmetric distribution are reported as mean \pm standard deviation, and continuous variables with asymmetric distribution as median with the 25th and 75th percentiles are reported as interquartile range. Univariate associations with postoperative MACE were determined for each preoperative and intraoperative variable (Appendix 1) using logistic regression analysis. Preoperative and intraoperative variables that exhibited some evidence of univariate association $(P<.1)$ were then included in a backward, stepwise, multifactorial logistic regression model (Appendix 2 ) to identify predictors for postoperative MACE. Statistical analysis was performed using the Statistical Package for the Social Sciences version 15.0 for Windows (SPSS Inc, Chicago, IL).

\section{RESULTS}

Table 1 shows the clinical profile of the 5171 study patients. Mean age was $65 \pm 9$ years, and $21.5 \%(\mathrm{n}=$ 1112) were female. The majority of patients $(\mathrm{n}=3656$, $70.7 \%)$ had 3-vessel disease, and 13.7\% $(\mathrm{n}=708)$ previously underwent angioplasty and stenting. Diabetes mellitus and peripheral vascular disease were present in $19.7 \%$ of patients $(n=1019)$ and $10.9 \%$ of patients $(n=564)$, respectively. Operations were predominantly elective $(n=4026$, 
TABLE 1. Clinical profiles of patients undergoing coronary artery bypass grafting

\begin{tabular}{|c|c|c|c|c|}
\hline Variable & All patients n (\%) & Patients without MACE* n (\%) & Patients with MACE* n (\%) & $P$ value \\
\hline No. of patients & 5171 & 4935 & 236 & \\
\hline \multicolumn{5}{|l|}{ Demographics } \\
\hline Female gender & $1112(21.5)$ & $1056(21.4)$ & $56(5.0)$ & .48 \\
\hline Mean age $(y) \pm S D$ & $65 \pm 9$ & $65 \pm 9$ & $68 \pm 9$ & $<.001$ \\
\hline \multicolumn{5}{|l|}{ Cardiac morbidity } \\
\hline Prior myocardial infarction & $2027(39.2)$ & $1896(38.4)$ & $131(55.5)$ & $<.001$ \\
\hline Congestive heart failure & $726(14.0)$ & $657(13.3)$ & $69(29.2)$ & $<.001$ \\
\hline Left ventricular ejection fraction & & & & $<.001$ \\
\hline 0.50 & 3889 (75.2) & $3775(76.5)$ & $114(48.3)$ & \\
\hline $0.30-0.50$ & 998 (19.3) & $936(19.0)$ & $62(26.3)$ & \\
\hline 0.30 & $284(5.5)$ & $224(4.5)$ & $60(25.4)$ & \\
\hline \multicolumn{5}{|l|}{ Angiographic findings } \\
\hline Extent of coronary artery disease & & & & $<.001$ \\
\hline Single vessel & $259(5.0)$ & $255(5.2)$ & $4(1.7)$ & \\
\hline Double vessel & $1256(24.3)$ & $1219(24.7)$ & 37 (15.7) & \\
\hline Triple vessel & 3656 (70.7) & $3461(70.1)$ & $195(82.6)$ & \\
\hline Left main stem disease & $1513(29.3)$ & $1417(28.7)$ & $96(40.7)$ & $<.001$ \\
\hline \multicolumn{5}{|l|}{ Graft details } \\
\hline \multicolumn{5}{|l|}{ Bypass graft territories } \\
\hline LAD & $4903(94.8)$ & $4678(94.8)$ & $225(95.3)$ & .71 \\
\hline RCA distribution & $3751(72.5)$ & $3566(72.3)$ & $185(78.4)$ & .04 \\
\hline Circumflex system & $3842(74.3)$ & $3671(74.4)$ & $171(72.5)$ & .50 \\
\hline Arterial conduits & $4603(89.0)$ & $4413(89.4)$ & $190(80.5)$ & $<.001$ \\
\hline LITA & 4559 (88.2) & 4370 (88.6) & $189(80.1)$ & $<.001$ \\
\hline
\end{tabular}

$C A B G$, Coronary artery bypass grafting; $L A D$, left anterior descending artery; $L I T A$, left internal thoracic artery; MACE, major adverse cardiac event; RCA, right coronary artery; $S D$, standard deviation. *MACE, a composite of postoperative myocardial infarction, regrafting for early postoperative graft failure, postcardiotomy shock requiring intraaortic balloon pump, or ventricular assist device in addition to inotropes and death in-hospital or within 30 days of operation.

$77.9 \%)$, and most patients $(n=3272,63.3 \%)$ received 3 or more bypass grafts. At least 1 grafted coronary was small in 2369 patients $(45.8 \%)$, and 2774 patients $(53.6 \%)$ had moderate/severe atherosclerosis of a dominant right coronary or left anterior descending artery.

\section{Characteristics of Grafted Coronary Arteries}

A total of 14,019 anastomoses were performed. The distribution of the coronary anastomoses is displayed in Table 2. The left anterior descending artery was grafted in $94.8 \%$ of patients $(\mathrm{n}=4903)$, the circumflex system was grafted in $74.3 \%$ of patients $(\mathrm{n}=3842)$, the right coronary artery or a tributary was grafted in $72.5 \%$ of patients $(n=3791)$, the diagonal branches were grafted in $18.7 \%$ of patients $(n=968)$, and the intermediate coronary artery was grafted in $4.0 \%$ patients $(n=205)$. Two branches each, of the circumflex and diagonal arteries, received bypass grafts in 5.6\% $(\mathrm{n}=$ $292)$ and $0.2 \%(n=9)$ of patients, respectively.

In general, 4460 of the 14,019 grafted coronaries $(31.8 \%)$ were $1.25 \mathrm{~mm}$ or less in diameter, and $5895(42.1 \%)$ had moderate/severe atherosclerosis. All grafted coronaries were small in 1091 patients $(21.1 \%)$, and half or more grafted coronaries were small in 1729 patients $(33.4 \%)$.

Of 4903 left anterior descending arteries, 1553 (31.7\%) were of small caliber and $2175(44.4 \%)$ had moderate/ severe atherosclerosis. Endarterectomy was performed in
28 patients $(0.6 \%)$. For the right coronary artery, 1235 of $3791(32.6 \%)$ were of small caliber and 1789 $(47.2 \%)$ had moderate/severe atherosclerosis. A right coronary artery endarterectomy was performed in 128 patients $(3.4 \%)$.

The circumflex system (obtuse marginal arteries) was of small diameter in 1311 of 4134 patients $(31.7 \%)$, and 1377 patients $(33.3 \%)$ had moderate/severe atherosclerosis.

There were notable gender differences in the characteristics of grafted coronary arteries. The female patients more frequently had small coronaries than the male patients $(P$ $<.0001$ ); more than half the grafted coronaries in $40.7 \%$ of women versus $31.5 \%$ of men, and all grafted coronaries in $28.0 \%$ of women versus $19.2 \%$ of men, were of small diameter. A greater proportion of women had a small left anterior descending artery compared with men $(39.4 \%$ vs $27.5 \%, P<.0001$ ), but a similar percentage of female to male patients $(25.1 \%$ and $23.5 \%, P=.28)$ had small right coronary arteries. Conversely, more men had moderate/severe atherosclerosis of the left anterior descending artery $(43.1 \%$ vs $38.3 \%$ for women, $P=.004)$ and the right coronary artery (36.1\% vs $29.2 \%$ for women, $P<.0001)$.

Myocardial revascularization was incomplete in $5.0 \%$ of patients $(\mathrm{n}=261)$. The incidence of incomplete revascularization was higher in women $(7.6 \%$ vs $4.4 \%, P<.0001)$. 
TABLE 2. Coronary characteristics of 5171 patients undergoing coronary artery bypass grafting

\begin{tabular}{|c|c|c|}
\hline Coronary characteristic & $\begin{array}{c}\text { Total no. of } \\
\text { measurements }\end{array}$ & Frequency $n(\%)$ \\
\hline Coronary size (mm) & 14,019 & \\
\hline 1.0 & & $316(2.3)$ \\
\hline 1.25 & & $4144(29.6)$ \\
\hline 1.50 & & $5562(39.7)$ \\
\hline 1.75 & & $2650(18.9)$ \\
\hline$\geq 2.0$ & & $1337(9.5)$ \\
\hline Coronary atherosclerosis & 14,019 & \\
\hline None & & $4454(31.8)$ \\
\hline Mild & & $3670(26.2)$ \\
\hline Moderate & & $3462(24.7)$ \\
\hline Severe & & $2433(17.4)$ \\
\hline Endarterectomy & & $170(1.2)$ \\
\hline Bypass conduits & 14,019 & \\
\hline Saphenous vein & & $8663(61.8)$ \\
\hline $\begin{array}{l}\text { Left internal thoracic } \\
\text { artery }\end{array}$ & & $4621(33.0)$ \\
\hline $\begin{array}{l}\text { Right internal thoracic } \\
\text { artery }\end{array}$ & & $148(1.1)$ \\
\hline Radial artery & & $585(4.2)$ \\
\hline Other & & $2(0)$ \\
\hline \multicolumn{3}{|l|}{ Coronary diameter $\leq 1.25 \mathrm{~mm}$} \\
\hline $\begin{array}{l}\text { Left anterior } \\
\text { descending artery }\end{array}$ & 4903 & $1553(31.7)$ \\
\hline Right coronary artery & 3791 & $1235(32.6)$ \\
\hline Circumflex & 4134 & $1311(31.7)$ \\
\hline Diagonal/intermediate & 1191 & 235 (19.7) \\
\hline \multicolumn{3}{|l|}{$\begin{array}{l}\text { Moderate/severe } \\
\text { atherosclerosis }\end{array}$} \\
\hline $\begin{array}{l}\text { Left anterior } \\
\text { descending artery }\end{array}$ & 4903 & $2175(44.4)$ \\
\hline Right coronary artery & 3791 & $1789(47.2)$ \\
\hline Circumflex & 4134 & $1377(33.3)$ \\
\hline Diagonal/intermediate & 1191 & $304(25.5)$ \\
\hline \multicolumn{3}{|l|}{ Endarterectomy } \\
\hline $\begin{array}{l}\text { Left anterior } \\
\text { descending artery }\end{array}$ & 4903 & $28(0.6)$ \\
\hline Right coronary artery & 3791 & $128(3.4)$ \\
\hline Circumflex & 4134 & $12(0.3)$ \\
\hline Diagonal/intermediate & 1191 & $4(0.3)$ \\
\hline
\end{tabular}

Diabetes did not exhibit a univariate association with coronary artery diameter or incomplete myocardial revascularization. However, compared with nondiabetic patients, diabetic patients were more likely to have moderate/severe atherosclerosis of the right coronary artery $(37.7 \%$ vs $34.0 \%, P=.03)$ and left anterior descending artery $(46.4 \%$ vs $41.2 \%, P=.003)$.

\section{Relationship Between Coronary Characteristics and Operative Outcome}

Postoperatively, MACE occurred in 236 patients (4.6\%): myocardial infarction without reintervention in 54 patients
$(10 \%)$, reintervention for early graft failure in 20 patients $(0.4 \%)$, significant postoperative hemodynamic instability requiring intraaortic balloon pump or ventricular assist device support additional to inotropic infusions in 72 patients $(1.4 \%)$, and operative mortality in 90 patients $(1.7 \%)$. Creatine kinase-MB or troponin $\mathrm{T}$, available for 25 of $68 \mathrm{pa}-$ tients with postoperative myocardial infarction, was elevated.

Univariate analysis revealed strong associations between coronary artery characteristics and MACE (Appendix 2). Whereas small caliber and moderate/severe atherosclerosis of the right coronary artery and moderate/severe atherosclerosis of the left anterior descending artery were associated with an increase in the incidence of MACE, a left internal thoracic artery graft decreased the risk. However, these associations were not maintained by multivariate analysis. The risk factors for MACE by multivariate analysis are shown in Table 3. Moderate/severe atherosclerosis of the left anterior descending artery (odds ratio [OR], 1.37; 95\% confidence interval $[\mathrm{CI}], 1.01-1.87 ; \quad P=.04)$, severe atherosclerosis of the right coronary requiring endarterectomy (OR, 2.45; 95\% CI, 1.21-4.98; $P=.01$ ), and incomplete revascularization (OR, $1.87 ; 95 \% \mathrm{CI}, 1.03-3.39$; $P=.04)$ retained a statistically significant association with MACE. Small coronary caliber affecting half or more of the grafted coronaries in a patient did not exhibit a significant independent influence on MACE (OR, 1.36; 95\% CI, 0.97-1.94; $P=.07$ ). Other postoperative complications are listed in Table 4.

\section{DISCUSSION}

Poor coronary characteristics are not uncommon in current practice. They increase the operative difficulty and complexity of CABG, and have been shown to be a frequent cause of modification of the " $a b$ initio revascularization strategy." 13,14 The present study reveals that small coronary artery targets and severe coronary atherosclerosis are common in patients undergoing $\mathrm{CABG}$, with up to $46 \%$ of patients with at least 1 coronary artery of small diameter $(\leq 1.25 \mathrm{~mm}), 21 \%$ of patients with small coronaries in all grafted territories, and $54 \%$ of patients with moderate/ severe atherosclerosis in 1 of the major target vessels. Although women were more likely to have small-diameter vessels, men more often had moderate/severe coronary atherosclerosis.

Coronary artery characteristics at the site of anastomoses directly affect the outcome of CABG. Our study shows that extensive atherosclerosis of the left anterior descending artery and diffuse severe atherosclerosis of the right coronary artery requiring endarterectomy were independent predictors of MACE after CABG. Apart from the technical challenges of constructing anastomoses in these settings, the associated morphologic and physiologic changes, such as a decrease in compliance, resistance and reactivity of 
TABLE 3. Risk factors by multivariate analysis for major adverse cardiac events after coronary artery bypass grafting

\begin{tabular}{lccc}
\hline \multicolumn{1}{c}{ Covariate } & OR & $\mathbf{9 5 \%}$ CI & $\boldsymbol{P}$ value \\
\hline Ejection fraction $<0.30$ & 7.31 & $4.92-10.86$ & $<.001$ \\
Emergency surgery & 3.66 & $1.56-8.58$ & .003 \\
Renal insufficiency & 2.69 & $1.35-5.36$ & .005 \\
Right coronary endarterectomy & 2.45 & $1.21-4.98$ & .01 \\
Incomplete revascularization & 1.87 & $1.03-3.39$ & .04 \\
Intravenous nitrates/heparin until surgery & 1.73 & $1.05-2.84$ & .03 \\
Peripheral vascular disease & 1.68 & $1.12-2.52$ & .01 \\
Previous stroke & 1.64 & $1.06-2.55$ & .03 \\
Moderate/severe atherosclerosis of left & 1.37 & $1.01-1.87$ & .04 \\
$\quad$ anterior descending artery & & & \\
Age & 1.04 & $1.02-1.06$ & $<.001$ \\
Cardiopulmonary bypass time & 1.01 & $1.01-1.02$ & $<.001$ \\
$\geq 50 \%$ grafted coronaries $\leq 1.25 \mathrm{~mm}$ in & 1.36 & $0.97-1.94$ & .07 \\
$\quad$ diameter & & & \\
\hline$C I$ Co & & & \\
\hline
\end{tabular}

$C I$, Confidence interval; $O R$, odds ratio.

the coronary vascular bed, and rigidity of the coronary artery, can compromise the adequacy of distal coronary flow. Nonsurgical series ${ }^{15}$ have shown that nonobstructive coronary disease and coronary calcification are associated with increased mortality. Similarly, an increase in the incidence of MACE has been observed after endarterectomy of the right coronary artery. ${ }^{16}$

Notable, and somewhat surprising, is our finding that constructing coronary anastomoses with small-diameter vessels $(\leq 1.25 \mathrm{~mm})$ per se did not significantly increase the risk of MACE in the early postoperative period after CABG. In view of the procedural difficulty of small-vessel anastomoses, this represents an improvement when compared with historical data, probably because of better technical skills resulting from a growing experience in dealing with these challenging cases that are more prevalent in current practice, as well as changes in surgical and perioperative care. For example, the historical data of the Northern New England Cardiovascular Disease Study Group ${ }^{10,11}$ demonstrated a strong association between the size of the left anterior descending artery and operative mortality. However, in those series, less than $80 \%$ of patients received an internal thoracic artery graft. Also, neither the influence of the size of other major coronary arteries nor the extent of atherosclerosis or incomplete revascularization was explored in these earlier studies. A possible explanation of our finding is provided by the data of Cigarroa and colleagues, ${ }^{17}$ which showed an increase in the size of the coronaries after bypass grafting. Small vessels in particular exhibited a significant increase in diameter postoperatively if they received arterial grafts. Another reason for our finding is the proclivity to underestimate or undergauge the size of chronically underfilled and collapsed coronaries that have the potential to open and dilate with improved antegrade blood flow after grafting. ${ }^{18}$ The reliability of angiography in determining the suitability of coronary size and degree of atherosclerosis for bypass grafting has also been questioned ${ }^{19,20}$ and was not considered in this study. Although our findings may seem counterintuitive, it is corroborated by the report of Mickleborough and associates. ${ }^{5}$ In their study, small vessel was not a predictor of postoperative myocardial infarction or operative mortality, but diffuse disease with or without endarterectomy had a univariate association with operative mortality. Notably, vessel quality did not influence long-term survival. Providing, therefore, it is technically feasible to construct an anastomosis on a coronary artery, small coronary diameter on its own should not be seen as a contraindication. The stronger consideration should be whether a viable anastomosis can be performed with the coronary artery rather than an anticipation of a poor outcome resulting from grafting small coronaries, especially in patients with good left ventricular function, as did the majority of patients in this study.

Increasing complexity of surgery for coronary artery disease, as often occurs with difficult coronary targets, is the principal cause of incomplete revascularization. ${ }^{21,22}$ Our study, as well as others, ${ }^{12}$ found a powerful correlation between incomplete revascularization and postoperative MACE. The contrasting impacts of small coronaries and incomplete revascularization on early operative outcome have major implications for intraoperative decision-making. The present study supports undertaking the challenging task of constructing anastomoses with small coronaries when technically feasible rather than abandoning these coronaries and causing incomplete myocardial revascularization, which increases the risk of early postoperative MACE. The present study also supports choosing to graft small coronaries over performing endarterectomy of the right coronary artery. Ramstrom and associates ${ }^{9}$ examined the effect of arterial grafts in patients with small-vessel disease (defined as $\leq 1.5 \mathrm{~cm}$ in diameter) in a small group of 200 patients. They reported higher early operative mortality among women, patients with "small-vessel disease," and patients with incomplete revascularization, but they did not have sufficient number of events to explore independent associations between operative mortality and any of these variables. Again, as in other previous studies, only single coronary territories were considered.

Our study replicates well-known findings regarding poor surgical outcome in female patients compared with male patients, ${ }^{23}$ and diabetic patients compared with nondiabetic patients, ${ }^{24}$ and showed that neither gender nor diabetes alone increased the risk of MACE. Although a prejudicial influence of coronary artery size was not established, this study highlights the influential roles of other factors, such as moderate and severe atherosclerosis of the left anterior descending artery, severe right coronary artery atherosclerosis requiring endarterectomy, and incomplete myocardial revascularization, on early outcomes. 
TABLE 4. Postoperative complications after coronary artery bypass grafting

\begin{tabular}{lc}
\hline \multicolumn{1}{c}{ Postoperative complications } & Frequency, $\mathbf{n}(\%) \mathbf{~ N}=\mathbf{5 1 7 1}$ \\
\hline Inotropes & $1073(20.8)$ \\
Reopening for bleeding/tamponade & $143(2.8)$ \\
Atrial fibrillation & $1437(27.8)$ \\
Neurologic dysfunction & $120(2.3)$ \\
Renal insufficiency & $264(5.1)$ \\
Readmission to intensive care & $129(2.5)$ \\
Pulmonary complications & $847(16.4)$ \\
Median postoperative & 6 (interquartile range, 6-8) \\
hospital days & \\
\hline
\end{tabular}

\section{Study Limitations}

In practice, the assessment of coronary size to inform the decision to graft or not to graft a vessel is subjective and can be further complicated by the unreliability of preoperative angiograms and underfilling of the vessels. The use of graduated probes, however, reduced the interobserver variability in this study. Another limitation is the lack of direct evaluation of graft patency. Because our patients did not routinely undergo intraoperative graft imaging or postoperative coronary angiography, these data were not available for scrutiny. Although this would have added a different perspective to this study, angiographic findings do not always correlate with clinical outcomes, which were the measures of interest in this study. Also, the diagnosis of postoperative myocardial infarction mainly on the basis of ECG changes may be criticized. The validity of cardiac biomarkers such as troponin $\mathrm{T}$, assayed in some of our patients, depends on the interval between the time of myocardial infarction and the blood test, and the appropriate level of the serum biomarker that indicates a cardiac event occurred. Both of these were uncertain in the majority of patients, and the level of troponin $\mathrm{T}$ consistent with postoperative myocardial infarction is still debatable. Although the American College of Cardiology/American Heart Association guidelines ${ }^{25}$ recommend the use of ECG and cardiac biomarkers for the diagnosis of postoperative myocardial infarction after noncardiac surgery, they recognize the high sensitivity of 12-lead ECGs and the limitations of biomarkers, which are even greater after cardiac surgery. However, there was complete concordance between cardiac enzyme increase and ECG changes in support of postoperative myocardial infarction in patients with both parameters. Finally, we did not have the necessary data to relate individual coronary artery anastomoses with outcomes for specific coronary territories; thus, we are not able to comment on the regional impact of the characteristics of individual coronaries.

\section{CONCLUSIONS}

Poor-quality coronary arteries are commonly encountered in patients undergoing $\mathrm{CABG}$ in current practice.
In our experience, up to $32 \%$ of target coronaries are small and $42 \%$ have moderate/severe atherosclerosis. If coronaries with a luminal diameter of $1.25 \mathrm{~cm}$ or more were considered ungraftable, $21 \%$ of our patients would be inoperable and $46 \%$ would have incomplete revascularization on the basis of size alone. Fortunately, this difficulty is not insurmountable in the current era. In our experience, grafting small coronaries when technically feasible did not increase the risk of early MACE. However, incomplete revascularization that can result from avoidance of small coronaries had a direct link with MACE in the early postoperative period. Our data also suggest that a strategy of grafting small coronaries is less likely to cause MACE compared with endarterectomy, especially of the right coronary artery. A prospective study is warranted to further clarify the impact of coronary characteristics on the late outcome of CABG.

\section{References}

1. Huang HW, Brent BN, Shaw RE. Trends in percutaneous versus surgical revascularization of unprotected left main coronary stenosis in the drug-eluting stent era: a report from the American College of Cardiology-National Cardiovascular Data Registry (ACC-NCDR). Catheter Cardiovasc Interv. 2006;68:867-72.

2. Yang ZK, Shen WF, Zhang RY, et al. Coronary artery bypass surgery versus percutaneous coronary intervention with drug-eluting stent implantation in patients with multivessel coronary disease. J Interv Cardiol. 2007;20:10-6.

3. Influence of diabetes on 5-year mortality and morbidity in a randomized trial comparing CABG and PTCA in patients with multivessel disease: the Bypass Angioplasty Revascularization Investigation (BARI). Circulation. 1997;96:1761-9.

4. Coronary artery bypass surgery versus percutaneous coronary intervention with stent implantation in patients with multivessel coronary artery disease (the Stent or Surgery trial): a randomised controlled trial. Lancet. 2002;360:965-70.

5. Mickleborough LL, Carson S, Ivanov J. Gender differences in quality of distal vessels: effect on results of coronary artery bypass grafting. J Thorac Cardiovasc Surg. 2003;126:950-8.

6. Zindrou D, Taylor KM, Bagger JP. Coronary artery size and disease in UK South Asian and Caucasian men. Eur J Cardiothorac Surg. 2006;29:492-5.

7. Bourassa MG, Lesperance J, Campeau L, Simard P. Factors influencing patency of aortocoronary vein grafts. Circulation. 1972;45(1 Suppl):I79-85.

8. Walker JA, Friedberg HD, Flemma RJ, Johnson WD. Determinants of angiographic patency of aortocoronary vein bypass grafts. Circulation. 1972;45(1 Suppl):I86-90.

9. Ramstrom J, Lund O, Cadavid E, Thuren J, Oxelbark S, Henze A. Multiarterial coronary artery bypass grafting with special reference to small vessel disease and results in women. Eur Heart J. 1993;14:634-9.

10. O'Connor GT, Morton JR, Diehl MJ, et al. Differences between men and women in hospital mortality associated with coronary artery bypass graft surgery. The Northern New England Cardiovascular Disease Study Group. Circulation. 1993;88(5 Pt 1):2104-10.

11. O'Connor NJ, Morton JR, Birkmeyer JD, Olmstead EM, O'Connor GT. Effect of coronary artery diameter in patients undergoing coronary bypass surgery. Northern New England Cardiovascular Disease Study Group. Circulation. 1996;93: $652-5$.

12. Kleisli T, Cheng W, Jacobs MJ, et al. In the current era, complete revascularization improves survival after coronary artery bypass surgery. J Thorac Cardiovasc Surg. 2005;129:1283-91.

13. Brown JM, Poston RS, Gammie JS, et al. Off-pump versus on-pump coronary artery bypass grafting in consecutive patients: decision-making algorithm and outcomes. Ann Thorac Surg. 2006;81:555-61.

14. Diegeler A, Matin M, Falk V, et al. Indication and patient selection in minimally invasive and off-pump coronary artery bypass grafting. Eur J Cardiothorac Surg. 1999;16(Suppl 1):S79-82.

15. Ostrom MP, Gopal A, Ahmadi N, et al. Mortality incidence and the severity of coronary atherosclerosis assessed by computed tomography angiography. $J$ Am Coll Cardiol. 2008;52:1335-43. 
16. Taggart DP. Biochemical assessment of myocardial injury after cardiac surgery: effects of a platelet activating factor antagonist, bilateral internal thoracic artery grafts, and coronary endarterectomy. J Thorac Cardiovasc Surg. 2000;120: 651-9.

17. Cigarroa RG, Lange RA, Hillis LD. Quantitative assessment of coronary arterial diameter before and after coronary artery bypass grafting. Am J Cardiol. 1989;64: 261-3.

18. Partridge JB, Brandt PW, Whitlock RM. The underfilled coronary artery: some pre- and post-operative observations on recipient arterial quality and left ventricular function after coronary artery surgery. Clin Radiol. 1978;29:5-8.

19. Pidgeon J, Treasure T, Brooks N, Cattell M, Balcon R. Correlation of angiographic and surgical findings in distal coronary branches. Br Heart J. 1984;51: 125-9.

20. Campeau L, Hunninghake DB, Knatterud GL, et al. Aggressive cholesterol lowering delays saphenous vein graft atherosclerosis in women, the elderly, and patients with associated risk factors. NHLBI post coronary artery bypass graft clinical trial. Post CABG Trial Investigators. Circulation. 1999;99:3241-7.

21. Lichtenberg A, Klima U, Paeschke H, et al. Impact of multivessel coronary artery disease on outcome after isolated minimally invasive bypass grafting of the left anterior descending artery. Ann Thorac Surg. 2004;78:487-91.
22. Scott R, Blackstone EH, McCarthy PM, et al. Isolated bypass grafting of the left internal thoracic artery to the left anterior descending coronary artery: late consequences of incomplete revascularization. J Thorac Cardiovasc Surg. 2000;120: 173-84.

23. Guru V, Fremes SE, Tu JV. Time-related mortality for women after coronary artery bypass graft surgery: a population-based study. J Thorac Cardiovasc Surg. 2004; 127:1158-65.

24. Filsoufi F, Rahmanian PB, Castillo JG, Mechanick JI, Sharma SK, Adams DH. Diabetes is not a risk factor for hospital mortality following contemporary coronary artery bypass grafting. Interact Cardiovasc Thorac Surg. 2007;6:753-8.

25. Fleisher LA, Beckman JA, Brown KA, et al. ACC/AHA 2007 guidelines on perioperative cardiovascular evaluation and care for noncardiac surgery: a report of the American College of Cardiology/American Heart Association Task Force on Practice Guidelines (Writing Committee to Revise the 2002 Guidelines on Perioperative Cardiovascular Evaluation for Noncardiac Surgery): developed in collaboration with the American Society of Echocardiography, American Society of Nuclear Cardiology, Heart Rhythm Society, Society of Cardiovascular Anesthesiologists, Society for Cardiovascular Angiography and Interventions, Society for Vascular Medicine and Biology, and Society for Vascular Surgery. Circulation. 2007;116:e418-99. 
APPENDIX 1. PREOPERATIVE AND INTRAOPERATIVE VARIABLES TESTED FOR UNIVARIATE ASSOCIATIONS WITH MAJOR ADVERSE CARDIAC EVENTS

\section{Categoric variables}

Angina severity using the Canadian Cardiovascular Society classification system (I, II, III, IV)

Prior myocardial infarction

Cardiac failure

Hypertension

Preoperative permanent pacemaker or defibrillator

Prior percutaneous intervention

Preoperative intravenous heparin and nitrates

Presence of left main stem disease

Left ventricular systolic function $(<0.30,0.30-0.50,>0.50)$

Diabetes

Renal insufficiency or dialysis (creatinine $>200 \mu \mathrm{mol} / \mathrm{L}$ )

Peripheral vascular disease

Previous stroke

Chronic obstructive airways disease

Sites of coronary anastomoses (left anterior descending, right coronary territory, circumflex system)

Size of coronary arteries at site of anastomoses (small [ $\leq 1.25 \mathrm{~mm}$ ], adequate [ $>1.25 \mathrm{~mm}])$

Extent of atherosclerosis of target coronaries (none/mild, moderate/severe)

Endarterectomy

Bypass conduits (left internal thoracic artery, others)

Incomplete revascularization

Priority of operation (elective, urgent, emergency)

\section{Continuous variables}

Age

Body mass index

No. of diseased coronary arteries

Cardiopulmonary bypass duration

Crossclamp time

APPENDIX 2. Univariate factors associated with major adverse cardiac events after coronary artery bypass grafting

\begin{tabular}{|c|c|c|c|}
\hline Variables & OR & $95 \%$ CI & $P$ value \\
\hline \multicolumn{4}{|l|}{ Ejection fraction } \\
\hline 0.30 & 9.78 & $6.98-13.71$ & $<.001$ \\
\hline $0.30-0.50$ & 2.17 & $1.57-3.0$ & $<.001$ \\
\hline \multicolumn{4}{|l|}{ Surgery priority } \\
\hline Emergency & 6.25 & $3.42-11.42$ & $<.001$ \\
\hline Urgent & 2.56 & $1.93-3.38$ & $<.001$ \\
\hline Renal insufficiency & 4.44 & $2.51-7.86$ & $<.001$ \\
\hline \multicolumn{4}{|l|}{ Congestive heart failure } \\
\hline Current & 4.21 & $2.98-5.96$ & $<.001$ \\
\hline Past & 1.81 & $1.12-2.90$ & .02 \\
\hline Intravenous nitrates/heparin & 3.74 & $2.72-5.12$ & $<.001$ \\
\hline Right coronary endarterectomy & 2.48 & $1.37-4.46$ & .002 \\
\hline Peripheral vascular disease & 2.45 & $1.77-3.39$ & $<.001$ \\
\hline Previous stroke & 2.07 & $1.42-3.01$ & $<.001$ \\
\hline Number of coronary artery diseased & 2.07 & $1.51-283$ & $<.001$ \\
\hline Incomplete revascularization & 1.82 & $1.13-2.93$ & .01 \\
\hline Prior myocardial infarction & 1.77 & $1.36-2.30$ & $<.001$ \\
\hline Chronic obstructive pulmonary disease & 1.71 & $1.19-2.46$ & .004 \\
\hline Left main stem disease & 1.71 & $1.31-2.24$ & $<.001$ \\
\hline $\begin{array}{l}\text { Moderate/severe atherosclerosis of left } \\
\text { anterior descending artery }\end{array}$ & 1.69 & $1.30-2.20$ & $<.001$ \\
\hline $\begin{array}{l}\text { Moderate/severe atherosclerosis of right } \\
\text { coronary artery }\end{array}$ & 1.56 & $1.19-2.03$ & .001 \\
\hline Diabetes mellitus & 1.43 & $1.05-1.94$ & .02 \\
\hline Right coronary artery graft & 1.38 & $1.0-1.89$ & .05 \\
\hline $\begin{array}{l}\text { Right coronary artery diameter } \\
\leq 1.25 \mathrm{~mm}\end{array}$ & 1.36 & $1.02-1.82$ & .04 \\
\hline$\geq 50 \%$ grafted coronaries $\leq 1.25 \mathrm{~mm}$ & 1.28 & $0.98-1.68$ & .07 \\
\hline $\begin{array}{l}\text { Left anterior descending artery } \\
\leq 1.25 \mathrm{~mm}\end{array}$ & 1.28 & $0.97-1.69$ & .08 \\
\hline Age & 1.04 & $1.03-1.06$ & $<.001$ \\
\hline Cardiopulmonary bypass duration & 1.01 & $1.01-1.02$ & $<.001$ \\
\hline Aortic crossclamp time & 1.01 & $1.0-1.02$ & .008 \\
\hline Left internal thoracic artery use & 0.55 & $0.38-0.76$ & $<.001$ \\
\hline
\end{tabular}

